The Impact of Nurses' Health on Productivity and Quality of Care

By: Susan Letvak, Christopher Ruhm, Susan Lane

This is a non-final version of an article published in final form in

Letvak, S. \& Ruhm, C., Lane, S. (2011). The impact of nurse health on productivity and quality of care. Journal of Nursing Administration, 41 (4), 162-167.

Made available courtesy of Lippincott, Williams, \& Wilkins:

http://dx.doi.org/10.1097/NNA.0b013e3182118516

***@ C Lippincott, Williams, \& Wilkins. Reprinted with permission. No further reproduction is authorized without written permission from Lippincott, Williams, \& Wilkins. This version of the document is not the version of record. Figures and/or pictures may be missing from this format of the document. $* * *$

\begin{abstract}
:
An aging workforce and high-stress environments have led to more nurses working with their own health problems, which in turn affects productivity. To assess this issue, the authors conducted focus groups with nurses and nurse managers. The authors discuss their findings and their implications for more proactively addressing issues that relate to health problems in nurses and the workplace changes that are needed to support nurses with health problems to ensure patient safety and quality care.
\end{abstract}

Keywords: Nursing | Health | Productivity | Quality of care

\title{
Article:
}

Hospital leaders are demanding a more productive workforce at a time of increased patient acuity, increasing governmental mandates, and an increased focus on patient safety and quality of care. A meta-synthesis of 94 research studies prepared for AHRQ demonstrated that a productive nursing workforce is vital to quality healthcare, ${ }^{1}$ and an important contributor to productivity is worker health. ${ }^{2}$ Nurses suffer from high rates of musculoskeletal pain and occupational injury, which have been found to contribute to reduced productivity. ${ }^{3,4}$ Although survey research has demonstrated that nurse health may lead to decreased productivity and concerns with quality of care, it is also important to understand how specific factors about nurse health, productivity, and quality of care can be used by nurse managers to better support their nurses.

\section{Work Productivity}

Major causes of decreased work productivity are health problems, especially musculoskeletal problems and mental health issues (primarily depression). ${ }^{5}$ More than $72 \%$ of workers with 
musculoskeletal and back pain report activity limitations, and 79.6\% report significant loss of productivity. ${ }^{6}$ Importantly, musculoskeletal disorders are reported in more than $60 \%$ of the RN workforce. ${ }^{7}$ Depressive disorders affect almost $10 \%$ of Americans older than 18 years. ${ }^{8}$ Given that work stress precipitates depression in working women and men, ${ }^{9}$ nurses are vulnerable to depression. One study found that $35 \%$ of a sample of 150 medical-surgical nurses had clinical depression. ${ }^{10}$ Depressed workers are more likely to make errors and are accident prone because of problems with concentration and focus associated with depression. ${ }^{11} \mathrm{~A}$ recent review of research studies of healthcare workers and the impact of health problems on productivity documented a positive relationship between common mental disorders and decreased performance, medication and equipment errors, needlestick injuries, and a decrease in patient safety. ${ }^{12}$

Research conducted in healthcare and other industries has documented that poor health can impact work productivity and, ultimately, job performance. However, no studies were found that documented the views of staff nurses and nurse managers about the impact of nurse health on productivity and patient safety and quality of care. These perceptions are critical if healthcare leaders are to effectively address these issues and make needed changes in the workplace.

\section{Methods}

\section{Focus Groups}

To address RNs' perspectives on nurse health and quality of care and patient safety, focus groups were conducted with 3 different groups of nurses: RNs who work with health problems themselves, RNs who do not have health problems but work with RNs who have health problems, and nurse managers who supervise RNs with health problems. Two focus groups with each group were conducted, for a total of 6 focus groups. We chose focus groups as our methods because they offer an efficient and reliable design for exploratory research questions. ${ }^{13}$ In addition, the group dynamic allows a nonthreatening and open exchange of information.

After obtaining institutional review board approval, participants were recruited by posting of flyers, announcements at unit staff meetings, and word of mouth by personal contact with nurse managers, directors of research, and clinical specialists at 4 hospital systems (6 different hospitals-4 community-based and 2 large teaching hospitals) located in different geographic regions of North Carolina. Inclusion criteria included self-identifying as being either an $\mathrm{RN}$ who was working in patient care with health problems, an RN who worked with RNs who experienced health problems, or a nurse manager directly responsible for RNs with health problems. Participants were recruited until 10 to 12 had agreed to participate in each group. Reminder phone calls and e-mails were sent to all who agreed to attend a focus group.

Participants were 28 RNs who worked at the hospitals. Despite larger numbers having committed to participate, group size ranged from 3 to 7 participants, which is within recommendations for optimum focus group size. ${ }^{13}$ Participants' privacy was maintained throughout the interviews by 
not disclosing their identity, hospital employed in, or any demographic data. Twenty-five RNs appeared to be white. Young, middle-aged, and older RNs participated. Only 1 of the 28 RNs was a man. In each focus group, homogeneity was retained by including members who met 1 of the 3 categories of participants (nurses with health problems, nurses who work with nurses with health problems, and nurse managers). Homogeneity was important to ensure group members as much freedom as possible to openly discuss situations and issues.

\section{Data Collection}

Focus groups were conducted by the same researcher in private conference rooms. To enhance a conversational tone and to ensure each group of nurses was asked similar questions, an openended, semistructured interview guide was used. Questions were developed from similar questions used by the researcher in previous research studies that used 1:1 interviews with nurses who worked with health problems. A total of 12 main questions were asked. For example, the first question was: "What are your experiences working with a health problem OR working with nurses with health problems OR managing nurses with health problems?" Other questions focused on asking how nurses compensate while working with health problems, if they disclose their health problems, and suggestions for assisting nurses with health problems. Each focus group was audio recorded to ensure accuracy of data collection and to allow the moderator to more fully participate in the discussions. Focus groups lasted between 60 and 90 minutes. Taperecorded interviews were transcribed verbatim by a skilled medical transcriptionist and checked for accuracy by the researchers and a research assistant.

Data Analysis

Data were analyzed following Krueger and Casey's ${ }^{14}$ content analysis strategies. Each transcript was read, and line-by-line coding was conducted of quotes pertaining to the experiences of the nurses, with special attention to issues concerning quality of care and patient safety. Quotes were organized by similar ideas and classified according to broad categories. The multiple broad categories were then organized into 4 overall themes. The research team worked together to ensure 100\% agreement on coding, categorizing, and developing themes.

Themes

There were 4 major themes that emerged from the focus group interviews: nurses' health problems are difficult for all, productivity and quality of care are impacted, we lack knowledge, and the work environment has to change.

Nurses' Health Problems Are Difficult for All

The first major theme was how a nurse's health problems are difficult for the nurse personally as well as others. Nurses with health problems mainly discussed suffering from pain (musculoskeletal and joint), although several openly discussed chronic insomnia, diabetes, heart 
disease, depression, and anxiety. These nurses continue to work, even on days when they feel very poorly, because of the impact their absence has on coworkers and loyalty to their patients. One nurse stated, "...we are dedicated to our jobs; we know that we have to care for patients. So you're very reluctant to call in sick unless you really are very ill. I think many of us have experienced coming into work when we really should have stayed home." Another said, "I think we continue to come in when we don't feel well because you have a sense of loyalty to your peers and... a sense of duty to patients." Other nurses talked about being penalized for taking sick time and rewarded for perfect attendance. "If we call in sick, it shows up on our evaluation. When we have perfect attendance for a quarter, we are given a certificate and a small bonus."

Whereas several nurses discussed having changed their work settings (eg, from critical-care units to outpatient surgery areas), most continued to do 12-hour shifts in high-stress environments. In addition, whereas most desired to continue to work despite their health problems, some of the nurses wished they could work less or choose less stressful jobs other than staff nursing; however, they had to work full time in the hospital because of education limitations or for insurance and financial issues. One nurse stated, "I think a lot of us older nurses who are working with our problems feel like we are stuck here because we've been at the institution many years and have gotten to a salary level we've gotten used to. We've built a lifestyle around that so we can't afford to go anyplace else."

The participants who work with nurses who are working with health problems were also impacted. One nurse stated, "These are sick nurses. Sicker than some of the patients they are taking care of. And, it's been very difficult watching them struggle over the years." Many were vocal about having to pick up the slack. One nurse stated, "I've experienced going into a room, and you need to pull a patient up in bed, and then if you go out and say, who can help me... it's like 'Oh I've torn my rotator cuff,' or... 'I'm pregnant,' so you end up pulling the patient up yourself." Some also felt that nurses with health problems create bad morale on a unit, and many have bad attitudes, focusing on what they cannot do rather than what they can do. One nurse stated, "They just come out as negative attitudes... and sometimes you want to look at them and say, 'if you are this miserable, go home.' All that negativism and sarcasm are just bringing us all down." A younger nurse respondent repeated several times, "We do not want to hear about other nurses' problems."

The nurse managers felt the major problems facing their staff nurses were musculoskeletal pain and depression from exhaustion and stress. Managers felt that, in general, nurses who work with health problems work longer hours to compensate, and the rest of the staff are usually supportive of these nurses. One manager stated, "Well I know a few of my nurses with health problems need more hours. For now I can overlook it-they need the time to finish their charting." Of interest, all of the managers stated they did not address health problems in nurses unless there were frequent absences or care was clearly being impacted. One manager stated, "As long as they do their job and the other staff aren't complaining, I can overlook things. If things to start to become more noticeable, well, I guess I will have to intervene." 
Productivity and Quality of Care Are Impacted

All 3 groups discussed how productivity and patient care are impacted by nurses who work with health problems. Specifically, nurses with health problems felt their health issues affected their ability to complete job tasks in a timely manner, impacted interpersonal interactions with coworkers and patients, altered their memory, interfered with their ability to properly document, decreased reaction time in emergencies, and inhibited their ability to physically provide care. These deficits all lead to possible issues with patient safety. One nurse stated, "Well my patients are probably dissatisfied, because I'm so far behind. I'm running in and out of the room so quickly and can't provide... and then I get aggravated because I don't feel good and can't provide the care I feel like I should, and this is felt by the patient too." Several of the nurses also talked openly about needing medications to get through the day. One stated, "So who are we kidding to think nurses aren't coming to work on things they shouldn't? And there is nothing wrong with that if it is going to help. Because if I didn't take it, how can I get through the day?"

Nurses who work with nurses who have health problems were more vocal about productivity and quality-of-care issues. Whereas some felt that these nurses were able to compensate by requesting easier assignments, doing charge more often, and relying on others to support them in their jobs, others felt that these nurses were not providing adequate physical care (eg, proper turning of patients to prevent pressure ulcers) and had less reaction time for emergencies (eg, could not run down the hall for a code). One nurse stated, "I worked in a psychiatric unit, and one of the nurses had bipolar disorder, she was very unstable at work. At times when she was rapid cycling, it was like, she was escalating, and the nurse became another person entirely, and you had to take care of her, and then the other patients started feeding off her, and it got kind of crazy."

Three respondents discussed nurses working under the influence of drugs to compensate for pain, and diverting to drugs meant for patients creating tremendous safety issues. One nurse stated, "I know there are a lot of nurses who are using medication that we don't even want to know aboutantianxiety meds, narcotics...." Another stated, "I have worked with people who have had substance abuse problems and have diverted medications from their patients. Working under the influence and diverting either fentanyl or meperidine (Demerol) in an emergency room setup, so obviously quality of care is impacted."

Managers were least likely to directly state that productivity and quality of care were being impacted. Although most of the participants discussed nurses with health problems needing assistance from other nurses, they felt other nurses accommodated them. One manager stated, "I know the other nurses pitch in to help (name) when she is having a bad day. My staff work as a team." Another stated, "I think the biggest issue is nurses who have pain are often a little short tempered. Our patient satisfaction surveys rate the nursing care, and I am sure these nurses receive lower scores." 


\section{We Lack Knowledge}

All of the nurses who participated in the focus groups identified a general lack of knowledge on how to identify and support nurses with health problems. The nurses who work with health problems expressed frustration with increasing demands placed on the bedside nurse and their perception that they are just "warm bodies" filling a spot. They felt a lack of support, especially from higher administration, and they did not feel the work environment supported them, openly talking about their health problems and needs. None of the nurses knew of any policies that would protect them in the workplace. When one nurse stated, "Well I thought that we had a policy here at this hospital that you could not take any medication within 4 to 6 hours that would impair your ability," others in the focus group quickly argued they never heard of such a policy. Another stated, "Well the managers need more education and resources. They need to know... what their options are: What can they do? ...In nursing we are famous for taking a really good floor nurse and putting her in management. They can help if they knew what to do."

The participants who worked with nurses who have health problems also had a lack of knowledge. Although several participants felt nurses openly could talk about their health problems, many felt that if these nurses were to openly discuss their health problems and medication regimens, they could lose their jobs. Nurses were much more comfortable discussing issues with pain and chronic illness than they were in discussing mental health issues. One participant stated, "There's a stigma if you had a psychological problem, it probably wouldn't be openly... they'll talk about the back pain, but they're probably not going to talk about the depression and anxiety." These nurses were mixed about management support, about half feeling their managers created open and supportive environments, whereas others felt managers were choosing to look the other away and were just "bad managers." Many felt that there needs to be more punitive action for nurses with productivity issues, especially those making repetitive errors, and the outright firing of nurses who are retained despite ongoing problems. One nurse stated, "My manager has been aware of several nurses and their performance issues for a long time, but she chooses to ignore it. All our new staff just leave the unit-and the problem nurses get to stay."

The nurse managers all agreed to having a general lack of knowledge and received limited training and communication from human resources concerning how to manage nurses with health problems. Although they agreed that $8 \%$ to $10 \%$ of their staff were working with significant health problems at any given time, they felt that they had little information about right-to-work laws or what their own legal protection was for confronting or dealing with these nurses. One manager stated, "Well I think some of it is the legal implications... so problems are not investigated. If we investigate, we'll know, and then we'll have to do something." Most of the managers felt there was a division between human resources and nursing management, and although they are required to document and address absenteeism issues on their units, there is little support or acknowledgement about health problems of nurses. 


\section{The Environment Has to Change}

The final theme identified was how the hospital work environment has to change. All of the groups felt that health problems in nurses will only increase as stress and aging of the workforce continue. The nurses with health problems who work were in universal agreement: flexibility in scheduling and the option of 8-hour shifts are essential. One nurse stated, "I think administration needs to take a more active role in looking at things, maybe job sharing, ... stop having nurses mandated to 12-hour shifts and offer 6-hour shifts." Other suggestions included fewer nurse-topatient ratios, improved unit design, better equipment, more ancillary personnel, more openness to discuss health problems, less computerization, and more support from nurse managers.

Nurses who work with nurses with health problems discussed similar suggestions to improving the work environment. There needs to be flexibility in scheduling, adequate staffing, wellness programs, decreased focus on computers and more focus on patient care, stress reduction programs, safe zones for communicating errors and concerns, and improved social environments so there is improved teamwork. One nurse stated, "Honestly, the environment doesn't allow nurses to be ill or have problems. It is all up to us to deal with it." They felt managers could immediately change negative environments because some managers are not adequately addressing problems, choosing to "ignore" rather than deal with unhealthy nurses.

Finally, the nurse managers also had suggestions for improving the work environment. The managers agreed that there needs to be flexibility in scheduling, new job design for older nurses and those with health problems, more resources for staff nurses, decreased workloads, decreased documentation, more equipment, a reduction in stress for staff nurses, and an increased focus on teamwork. Two of the respondents also felt that the Joint Commission was increasingly responsible for the stressful environments, leading to more stress and health problems in nurses. Of note, none of the managers identified that they directly needed to play a greater role. They felt they were accommodating nurses with health problems and trying to schedule properly so nurses with health problems are supported by adequate staffing as much as possible. Most of their suggestions were general work environment issues that were largely out of their own control.

\section{Discussion}

Pending healthcare reform that will likely bring decreased reimbursement and increased pressure on hospital leaders to decrease costs while assuring high quality of care will increase pressure on an already stressed nursing workforce. High-stress environments, as well as the aging of the workforce, will lead to continued health concerns in nurses themselves. Currently, little is being done to address nurse health and, more importantly, how nurse health is impacting productivity and quality of care. Nurses with health problems are working without flexibility in scheduling or the ability to call out sick when they are not feeling well. They lack knowledge of policies and their legal rights concerning worker rights. They also are often fearful of talking to their 
managers about their health problems. Trust between staff and the nurse manager is essential for nurse retention and positive patient outcomes. ${ }^{15}$

Whereas nurses who have health problems are clearly under duress as they try to manage 12hour shifts, high stress, and increasing patient care demands, this study uniquely documents that these nurses' coworkers are also impacted. Nurses voiced they came to work out of loyalty to their peers, yet many of their coworkers felt they should not have come to work and were actually a burden. Although the managers who participated in this study indicated that the coworkers were willing to pick up the slack, these nurses clearly voiced anger and frustration with their increased workload, negative attitudes of some nurses, patient safety concerns, and a lack of management support with these issues. Problems with team building, communication, and managerial awareness of staff concerns were identified. This finding supports Schmalenberg and Kramer's ${ }^{16}$ views that the behaviors of nurse managers that staff nurses perceive as supportive may or may not be the same as the behaviors that nurse managers think are supportive.

This study also documents the general lack of knowledge of nurses and managers concerning healthcare issues in nursing staff. Nurses with health problems do not feel they can openly talk to their managers for fear of losing their jobs or about policies that may be available to support them in their jobs. Nurses who work with nurses with health problems do not know what they can openly talk about with these nurses and are also unaware of policies. Most importantly, managers themselves seem to be ignoring the issue for fear of liability when talking about personal issues with their staff. They also had a lack of knowledge about their legal rights concerning talking about health issues and about worker policies and programs that exist. The managers felt a disconnect and a lack of support from human resources departments.

Clearly, efforts must be made to address problems in the hospital work environment. Nurse managers play a major role in creating productive work environments for staff nurses. Managers must work together and feel empowered to create the changes needed that will lead to improved conditions for nurses with health problems, as well as all nurses, so they remain healthy. It is time that 12-hour shifts be discontinued for nurses who want to work 8-, 6-, or even 4-hour shifts. Geiger-Brown and Trinkoff ${ }^{17}$ also argue that 12-hour shifts decrease performance in nurses and need to be reconsidered, despite their popularity. Benefits need to be provided for part-time work. Redesigned work roles need to be developed. More focus needs to be placed on productivity problems, especially when quality of care and patient safety are at risk. It is also not fair to coworkers, who already have full loads, to continually have to pick up the slack.

Finally, nurse managers must educate themselves about their legal rights and policies in their states and institutions concerning worker health. Human resource professionals in institutions have the knowledge and information needed by managers. In addition to providing in-service education and updates on new policies and laws, monthly team meetings could take place where managers could openly, and confidentially, discuss issues with their nurses and receive 
information and support. Information then needs to be shared at staff meetings so staff nurses, who also lack knowledge, can also become educated.

\section{Conclusion}

Nurses who have health problems impact staff productivity and quality of care, as well as present issues that affect the nurse, those who work with him/her, and management. Staff nurses and managers have a general lack of knowledge concerning legal rights and policies concerning worker health. Although certain work environment changes (including scheduling changes) could support nurses with health problems, they can be difficult to implement in a time of economic constraint. However, with education and open dialogue, nurses and nurse managers can work together to provide support nurses with health problems and provide healthier work environments for all nurses.

\section{References}

1. Kane RL, Shamliyan TA, Mueller C, Duval S, Wilt TJ. Nurse Staffing and Quality of Patient Care. AHRQ Publication 07-E005. 2007. Available at http://purl.access.gpo.gov/GPO/LPS81279. Accessed September 5, 2010.

2. Allen $\mathrm{H}$. Using routinely collected data to augment the management of health and productivity loss. J Occup Environ Med. 2008;50:615-632.

3. Allen H, Hyworon Z, Colombi A. Using self reports of symptom severity to measure and manage workplace depression. J Occup Environ Med. 2010;52:363-374.

4. Letvak S, Buck R. Factors influencing work productivity and intent to stay in nursing. Nurs Econ. 2008;26:159-166.

5. Lerner D, Henke RM. What does research tell us about depression, job performance, and work productivity? J Occup Environ Med. 2008;50:401-410.

6. Ricci JA, Stewart WF, Chee E, et alBack pain exacerbations and lost productive time costs in United States workers. Spine. 2006;31:3052-3060.

7. Lipscomb J, Trinkoff A, Brady B, Geiger-Brown J. Health care system changes and reported musculoskeletal disorders among registered nurses. Am J Public Health. 2004;94:1431-1435.

8. National Institute of Mental Health. The numbers count: mental disorders in America. 2008. Available at http://www.nimh.nih.gov/health/publications/the-numbers-count-mental-disordersin-america. Accessed October 1, 2010.

9. Melchior M, Caspi A, Milne BJ, Danese A, Poulton R, Moffitt TE. Work stress precipitates 
depression and anxiety in young working women and men. Psychol Med. 2007;37:1119-1129.

10. Welsh D. Predictors of depressive symptoms in female medical-surgical nurses.Issues Ment Health Nurs. 2009;30:320-326.

11. Jacob IG. Depression's impact on safety. Occup Health Saf. 2006;75:32-40.

12. Gartner FR, Nieuwenhuijsen K, van Dijk JH, Sluiter JK. The impact of common mental disorders on the work functioning of nurses and allied health professionals: a systematic review. Int J Nurs Stud. 2010;47:1047-1061.

13. Morgan D. Focus Groups as Qualitative Research. Thousand Oaks, CA: Sage; 2006.

14. Krueger RA, Casey MA. Focus Groups: A Practical Guide for Applied Research. Thousand Oaks, CA: Sage; 2000.

15. Rogers AE, Dean GE, Hwang W-T, Scott LD. Role of registered nurses in error prevention, discovery and correction. Qual Saf Healthc. 2008;17:117-121.

16. Schmalenberg C, Kramer M. Types of intensive care units with the healthiest, most productive work environments. Am J Crit Care. 2007;16(5):458-468.

17. Geiger-Brown J, Trinkoff AM. Is it time to pull the plug on 12-hour shifts? J Nurs Adm. 2010;40(3):100-102. 